\title{
POLA ORDINANSI KOMUNITAS POHON DI HUTAN SEKUNDER DISTRIK MANOKWARI UTARA KABUPATEN MANOKWARI
}

\section{(Ordinance Pattern of Secondary Forest Tree Community in Manokwari Utara Sub- district, District of Manokwari)}

\author{
INAREN MARKUS HUBY ${ }^{1}$, JIMMY F. WANMA ${ }^{1 凶}$, MARIANA H. PEDAY ${ }^{2}$ \\ Program Studi Kehutanan, Fakultas Kehutanan Universitas Papua Manokwari, Papua Barat, 98314. Tlp/Fax: \\ +62986211065 .
}

Program studi Manajemen Hutan Alam Produksi, Fakultas Kehutanan Universitas Papua Manokwari, Papua Barat, 98314 Tlp/Fax: +62986211065.

${ }^{\square}$ Penulis Korespondensi: Email: jimmywanma@yahoo.com

Diterima: 07 Feb 2020| Disetujui: 20 Mar 2020

\begin{abstract}
Abstrak. Tujuan dari penelitian ini adalah untuk mengetahui jenis-jenis tumbuhan indikator pada hutan sekunder, dengan menggunakan pendekatan deksriptif dan observasi lapang serta mengacu pada metode releve. Dari hasil penelitian ini diperoleh data vegetasi yang terdiri dari tumbuhan berkayu semai, pancang, tiang dan pohon yang dianalisis dengan menggunakan sofware MVA.4 (TWINSPAN) sehingga diperoleh 12 kelompok asosiasi dan 1 kelompok asosiasi soliter dimana kelompok ini terdiri dari jenis-jenis dominan. Adapun jenis-jenis yang sering muncul pada 12 kelompok asosiasi berdasarkan bentuk pertumbuhan yaitu Actinodaphne nitida, Celtis latifolia, Hemappasandra sp., Teijmaniodendron sp., Lea acuelata, Spatiostemon jevensis, Koordersiodendron pinnatum, Sisipus sp., Sterculia macrophylla, Litsea timoriana, Macaranga sp., Aglaia sp., Rhus taitensis, Alstonia scholaris, Archidendron parviflorum, Callophylum inophylum dan Ficus sp. Sedangkan jenis yang dominan pada kelompok soliter adalah Chisocheton ceremicus, Cryptocarya sp., Canarium hirsutum, Euodia elleryana, Litsea ladermani dan Litsea timoriana. Jenis-jenis tersebut merupakan jenis yang menyusun tegakan dominan pada hutan sekunder daerah di wilayah Manokwari utara Kabupaten Manokwari. Kata kunci: jenis dominan, asosiasi soliter, indikator, ekosistem, regenerasi alami
\end{abstract}

Kata kunci: jenis dominan, asosiasi soliter, indikator, ekosistem, regenerasi alami

Abstract. This study aimed to reveal indicator plant species in secondary forest through applying descriptive approach and field observation as well as refer to releve method. From the results noted several vegetation data of vascular plant at seedlings, saplings, poles, and tree stages that analyzed using MVA.4 (TWINSPAN) software. The analyzed result indicated 12 group of associations and 1 group of solitary association in which the species were categorized as dominant. The most often appear species in 12 association group based on their growing shapes were Actinodaphne nitida, Celtis latifolia, Hemappasandra sp., Teijmaniodendron sp., Lea acuelata, Spatiostemon jevensis, Koordersiodendron pinnatum, Sisipus sp., Sterculia macrophylla, Litsea timoriana, Macaranga sp., Aglaia sp., Rhus taitensis, Alstonia scholaris, Archidendron parviflorum, Callophylum inophylum and Ficus sp. While the most dominant species in the solitary association were Chisocheton ceremicus, Cryptocarya sp., Canarium hirsutum, Euodia elleryana, Litsea ladermani, and Litsea timoriana. These 
species arranged and functioned as the dominant tree structure in secondary forest along north Manokwari area of Manokwari.

Keywords: dominant species, solitary association, indicator, ecosystem, natural regeneration

\section{PENDAHULUAN}

Hutan adalah suatu hamparan lahan yang di dalamnya berisi masyarakat tumbuh-tumbuhan yang kompleks dan terdiri dari berbagai ukuran pohon sehingga dapat membentuk suatu susunan vegetasi tegakan yang terdapat di suatu areal tertentu (Soerianegera dan Indrawan 2005). Vegetasi hutan merupakan salah satu bagian dari sumber daya alam yang bersifat dinamis dan memiliki tingkat keragaman jenis yang tinggi (biodiversity) berupa flora dan fauna beserta sumberdaya lainya yang dapat dimanfaatkan dan dikelolah oleh manusia untuk menunjang proses kehidupan. Vegetasi hutan menurut kondisi struktur dan komposisi jenisnya dikelompokan menjadi dua yaitu hutan sekunder dan primer.

Hutan sekunder adalah hutan primer yang ditebang untuk memenuhi kebutuhan kayu oleh manusia atau dibuka untuk ladang, atau terbuka karena bencana alami lain, kemudian secara alami terbentuk hutan baru, yang belum mencapai klimaks seperti hutan semula. Menurut Lamprecht (1986) hutan sekunder adalah hutan yang tumbuh dan berkembang secara alami sesudah terjadi kerusakan atau perubahan pada hutan yang pertama. Hutan sekunder merupakan fase pertumbuhan hutan dari keadaan tapak gundul, karena alam ataupun antropogen, sampai menjadi klimaks kembali. Catterson (1994) mendefinisikan hutan sekunder sebagai suatu bentuk hutan dalam proses suksesi yang mengkolonisasi areal-areal yang sebelumnya rusak akibat sebab-sebab alami atau manusia, dan yang suksesinya tidak dipengaruhi oleh vegetasi asli di sekitarnya karena luasnya areal yang rusak. Beberapa ciri dari hutan sekunder yaitu (1) komposisi dan struktur tidak saja tergantung tapak namun juga tergantung pada umur; (2) tegakan muda berkomposisi dan struktur lebih seragam dibandingkan hutan aslinya; (3) tak berisi jenis niagawi atau jenis-jenis yang lunak dan ringan, tidak awet, kurus dan tidak laku; (4) persaingan ruangan dan sinar yang intensif sering membuat batang bengkok; (5) jenis-jenis cepat gerowong atau riap awal besar, lambat daun mengecil; (6) karena struktur, komposisi dan riapnya tidak akan pernah stabil, sulit merencanakan pemasaran hasilnya.

Pertumbuhan tegakan adalah perubahan sifat-sifat dari suatu tegakan dan suatu laju perkembangan biologi menurut waktu pada pertambahan pohon atau tegakan selama jangka waktu tertentu karena perubahan jumlah tegakan yang dapat dipanen pada waktu tertentu (Beer 1962). Adapun perubahan tersebut terdiri dari pertambahan dan pengurangan jenis tumbuhan dari setiap jenis tumbuhan per individunya, sehingga sering terdapat areal yang kosong pada hutan primer dimana areal tersebut sedang mengalami suatu proses yaitu proses suksesi primer. Kondisi ini dapat terjadi karena beberapa faktor alami seperti kebakaran hutan, serangan hama dan penyakit, banjir dan tanah longsor, hal ini yang menyebabkan kondisi suatu hutan selalu berubah - ubah.

Pertumbuhan dan hasil suatu tegakan hutan dapat diukur dalam satuan fisik (volume) dan satuan nilai (kepentingan) untuk menetukan suatu struktur pertumbuhan tegakan pada hutan primer. Komponen pertumbuhan seperti riap sebagai akibat pertumbuhan dan jumlah jenis yang menyusun suatu tegakan selalu bersifat dinamis. Struktur pertumbuhan terbentuk dari pohon - pohon pada tingkat semai sampai pohon yang dihitung sebagai penyumbang pertumbuhan tegakan (Prasetyo 2006). 
Berbagai bentuk pengelolaan hutan telah dilakukan dengan menganut suatu sistem pengelolaan hutan berbasis ekosistem (forest ecosystem management) berdasarkan fungsi dan pengaruhnya dengan beberapa faktor yang terkait hutan. Namun pengelolaan tersebut belum memaksimalkan kelestarian suatu ekosistem hutan dimana eksplotasi hasil hutan yang selalu menggunakan alat - alat berat dalam memanen hasil hutan kayu di beberapa kawasan hutan primer khususnya di Provinsi Papua dan Papua Barat.

Pertambahan jumlah penduduk dan kebutuhan ekonomi menyebabkan masyarakat yang berada di kampung Mubraidiba pada umumnya telah mengelola kawasan hutan dengan melakukan pembukaan beberapa areal hutan primer dan sekunder untuk dijadikan kawasan perlandangan dengan sistem seleksi jenis atau menebang pohon-pohon kecil di bawah tegakan yang berukuran besar atau membakarnya. Namun sistem seleksi jenis ini hanya untuk periode tertentu, apabila tanaman telah tumbuh dan dipanen selanjutnya masyarakat akan tinggalkan areal hutan tersebut sambil dijaga sampai periode tertentu untuk kembali ditanami, sistem ini dikenal dengan sebutan perladangan berpindah. Areal hutan yang ditinggalkan berubah menjadi hutan sekunder yang selalu berubah-ubah struktur dan komposisi jenis tumbuhannya. Pohon pada tingkat semai sampai pohon yang di hitung sebagai penyumbang pertumbuhan tegakan (Prasetyo 2006).

Berbagai bentuk pengelolaan hutan telah dilakukan dengan menganut suatu sistem pengelolaan hutan berbasis ekosistem (forest ecosystem management) berdasarkan fungsi dan pengaruhnya dengan beberapa faktor yang terkait hutan. Namun pengelolaan tersebut belum memaksimalkan kelestarian suatu ekosistem hutan dimana eksplotasi hasil hutan yang selalu menggunakan alat - alat berat dalam memanen hasil hutan kayu di beberapa kawasan hutan primer khususnya di Provinsi Papua dan Papua Barat.

Pertambahan jumlah penduduk dan kebutuhan ekonomi menyebabkan masyarakat yang berada di kampung Mubraidiba pada umumnya telah mengelola kawasan hutan dengan melakukan pembukaan beberapa areal hutan primer dan sekunder untuk dijadikan kawasan perlandangan dengan sistem seleksi jenis atau menebang pohon-pohon kecil di bawah tegakan yang berukuran besar atau membakarnya. Namun sistem seleksi jenis ini hanya untuk periode tertentu, apabila tanaman telah tumbuh dan dipanen selanjutnya masyarakat akan tinggalkan areal hutan tersebut sambil dijaga sampai periode tertentu untuk kembali ditanami, sistem ini dikenal dengan sebutan perladangan berpindah. Areal hutan yang ditinggalkan berubah menjadi hutan sekunder yang selalu berubah-ubah struktur dan komposisi jenisnya tumbuhannya. Tujuan penelitian ini adalah mengetahui jenis-jenis indikator dalam setiap kelompok asosiasi yang terbentuk di hutan sekunder Mubraidiba kabupaten Manokwari. Manfaat yang ingin diperoleh dari penelitian adalah tersedianya informasi ekologi vegetasi mengenai deskripsi hutan sekunder kampung Mubraidiba yang selanjutnya dapat digunakan sebagai acuan untuk penelitian-penelitian lanjutan.

\section{METODOLOGI PENELITIAN}

\section{Waktu dan Obyek}

Penelitian ini dilaksanakan pada areal hutan sekunder kampung Mubraidiba distrik Manokwari Utara yang mulai dari tanggal 11 Oktober sampai dengan tanggal 15 Desember tahun 2013. Adapun objek dari penelitian adalah jenis-jenis tumbuhan berkayu berdasarkan tingkatan pertumbuhan yang terdapat pada areal hutan sekunder di kampung Mubradiba. 


\section{Metode Penelitian}

Metode yang digunakan dalam penelitian ini adalah metode deskriptif dengan teknik survei. Teknik dilakukan dengan mengadakan observasi lapangan dan studi pustaka untuk menganalisis permudaan tegakan yang tumbuh pada hutan sekunder.

\section{Variabel Pengamatan}

Variabel yang diamati dalam penelitian meliputi (1) nama jenis, famili dan jumlah individu per jenis serta (2) proyeksi luas tutupan tajuk tiap jenis pohon terhadap permukaan tanah dalam plot-plot pengamatan.

\section{Tahapan Pelaksanaan Penelitian}

\section{Persiapan Penelitian}

Adapun persiapan yang dilakukan dalam penelitian ini meliputi: persiapan alat dan bahan yang digunakan di lokasi penelitian. Selanjutnya melakukan kordinasi pada beberapa pihak yang terkait seperti kepala distrik Manokwari Utara dan kepala Kampung Mubraidiba. Kegiatan survei awal dilakukan dengan meninjau lokasi penelitian yang bertujuan untuk menentukan tata letak base line dan jalur pengamatan dan sekaligus melihat kondisi areal pengamatan, adapun lokasi penelitian tersebut terdapat di dalam wilayah administrasi kampung Mubraidiba distrik Manokwari Utara.

\section{Penentuan jalur dan petak pengamatan}

Penentuan jalur dan petak pengamatan dibuat dengan metode jalur berpetak dimana dalam suatu areal hutan sekunder dibuat suatu garis utama (base line) dengan arah horisontal yang nantinya diletakan 6 buah jalur yang memiliki panjang jalur $250 \mathrm{~m}$ dan 6 buah jalur dengan arah vertical dan didalam jalur tersebut terdapat 5 buah petak pengamatan dengan bentuk persegi (bujur sangkar) serta memiliki ukuran yang sebagaimana telah dibuat berdasarkan tingkatan pertumbuhan tegakan.

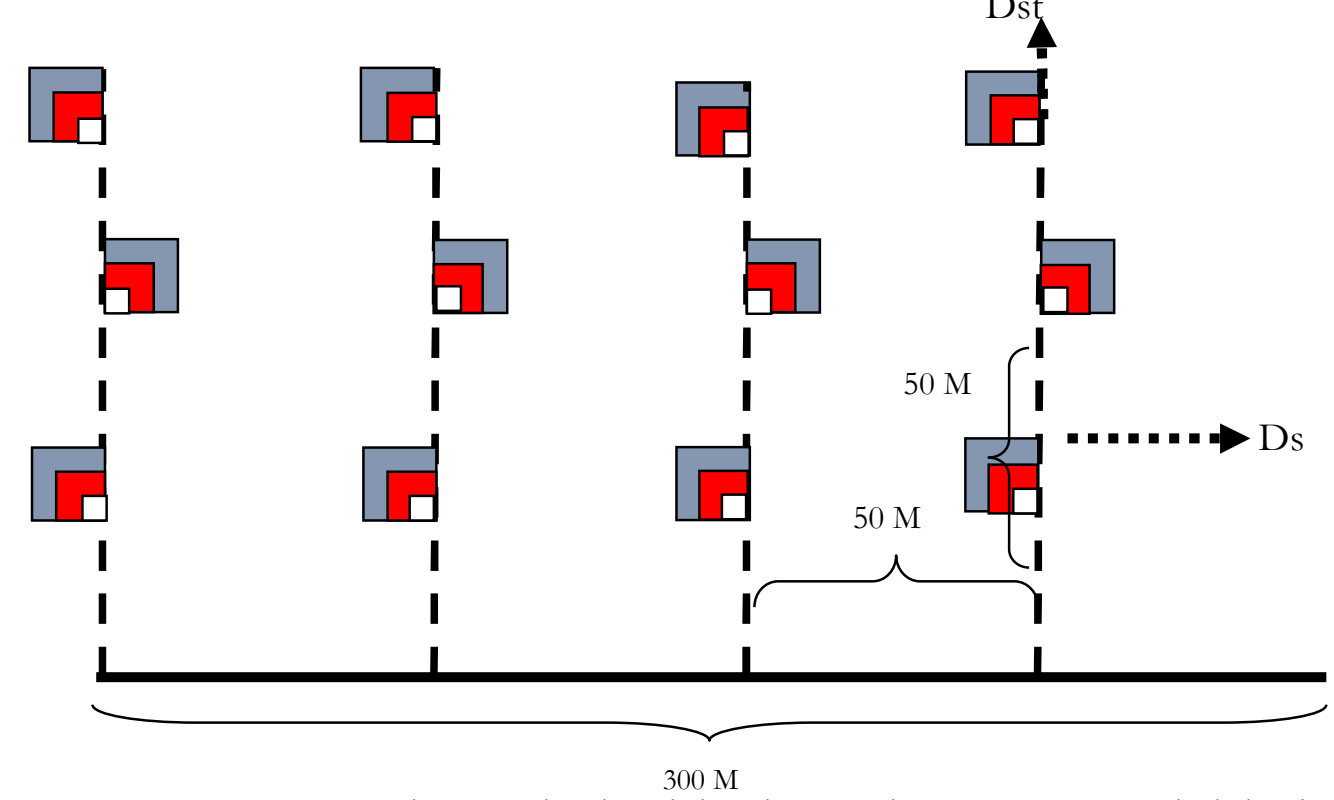

Gambar 1. Sketsa peletakan jalur dan petak pengamatan pada lokasi penelitian 
Keterangan:

- : Base line pengamatan

.... : Anak jalur pengamatan

$\square$ : Petak pengamatan dengan ukuran $10 \mathrm{~m} \times 10 \mathrm{~m}$ untuk tumbuhan tingkat tiang dan pohon

$\square$ : Petak pengamatan dengan ukuran $5 \times 5 \mathrm{~m}^{2}$ untuk tumbuhan tingkat pancang

: Petak pengamatan dengan ukuran $2 \times 2 \mathrm{~m}^{2}$ untuk tumbuhan tingkat semai

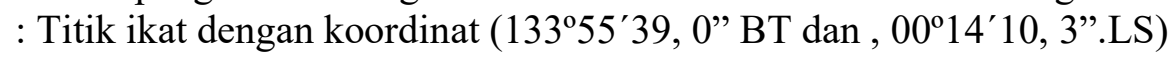

\section{Pengumpulan Data}

Data yang dikumpulkan dalam penelitian ini untuk setiap jumlah jenis individu berdasarkan tingkatan pertumbuhan yaitu (1) nama dan jumlah jenis yang terdapat pada lokasi penelitian, (2) nilai diameter tutupan tajuk, (3) pendataan tumbuhan tingkat semai, (4) pendataan tumbuhan tingkat pancang, (5) pendataan tumbuhan tingkat tiang dan (6) pendataan tumbuhan tingkat pohon.

Pendataan meliputi jumlah jenis untuk setiap fase pertumbuhan dan diidentifikasi dengan mengunakan buku indentifikasi flora dan dibantu oleh seorang pengenal jenis pohon sedangkan untuk diameter tajuk (cover) yang dilakukan pengamatan atau penilaian dengan melakukan pengukuran secara langsung terhadap suatu jenis tumbuhan yang terdapat dalam petak pengangamatan. Hasil pengukuran di ameter tajuk dinyatakan dalam persen penutupan tajuk yang menggunakan pada ketetapan nilai mengacu pada sekala dan nilai Braun Blanquet dalam Minnesota Departement Of Natural Resources (2007), data penelitian tersebut diperoleh secara langsung di lapangan.

\section{Pendataan Tumbuhan Berdasarkan Tingkatan Pertumbuhan}

a. Pendataan tumbuhan Tingkat semai

Kegiatan untuk pendataan tingkat bawah atau semai meliputi nama jenis dan (cover percentage) tiap individu semai dalam luasan petak pengamatan ukuran $2 \times 2 \mathrm{~m}$.

b. Pendataan tumbuhan tingkat pancang
Kegiatan untuk pendataan tingkat pancang meliputi pendataan nama jenis tiap individu pada tumbuhan tingkat pancang (sampling), dengan luasan petak untuk pengambilan sempel yaitu $5 \times 5 \mathrm{~m}$.

c. Pengukuran tingkat tiang dan pohon

Kegiatan pengukuran tingkat tiang dan pohon meliputi pendataan nama jenis tiap individu pada tingkat tiang (poles) dan tingkat pohon (trees), dengan luasan petak pengambilan sampel yaitu $10 \times 10 \mathrm{~m}$.

\section{Pengukuran Crown Cover (CC) dan Perhitungan Cover Percentage (CP)}

Crown cover (CC) untuk setiap individu dalam setiap plot diukur menggunakan meter roll. Pengukuran pertama dilakukan terhadap proyeksi tajuk terluas di atas permukaan tanah $\left(D_{l}\right)$ dan pengukuran ke dua dilakukan terhadap proyeksi tajuk tersempit di atas permukaan tanah $\left(D_{2}\right)$. Cover percentage $(\%)$ dari tiap jenis dalam plot akan dihitung menggunakan nilai hasil perhitungan Crown cover setelah dimasukkan ke dalam kategori berdasarkan nilai dan skala Braun Blenquet.

\section{Pengolahan Data}

1. Perhitungan luas $\mathrm{CC}$ dari jenis dalam tiap plot pengamatan menggunakan persamaan :

$$
\text { Crown cover }=\left(\frac{D_{1}+D_{2}}{4}\right)^{2} x \pi
$$

Keterangan :

$$
\begin{aligned}
& \mathrm{CC}=\text { Crown cover } \\
& \mathrm{D} 1=\text { Pengukuran diameter tajuk ke } 1(\mathrm{~m})
\end{aligned}
$$


D2 = Pengukuran diameter tajuk ke 2 (m) $\Pi=3,14$

2. Perhitungan $C P(\%)$ dari jenis dalam tiap plot pengamatan menggunakan persamaan :

Cover Percentage $(\%)=\frac{\text { Luas Tajuk Species }}{\text { Luas petak pengamatan }} \times 100 \%$

Hasil perhitungan $C P(\%)$ akan digunakan untuk menentukan nilai tutupan tajuk menurut kriteria atau skala Braun Blenquet.

Tabel 1. Tabel Persentase tutupan tajuk

\begin{tabular}{ccc}
\hline No. & Penutupan tajuk & Cover $(\%)$ \\
\hline 1. & 10 & 100 \\
2. & 9 & $76-99$ \\
3. & 8 & $>75$ \\
4. & 7 & $50-75$ \\
5. & 6 & $33-50$ \\
6. & 5 & $25-33$ \\
7. & 4 & $10-25$ \\
8. & 3 & $5-10$ \\
9. & 2 & $1-5$ \\
10. & 1 & $<1$ \\
11. & + & $\rightarrow$ \\
\hline
\end{tabular}

Sumber: Mueller-Dombois dan Ellenberg (1974).

\section{Analisis Data}

Data hasil perhitungan persen tutupan tajuk atau $C P(\%)$ akan dianalisis lebih lanjut menggunakan metode ordinansi komunitas dengan bantuan Software multivariate analysis, Twinspan for Windows Version 2.3. kemudian hasilnya ditampilkan dalam bentuk table dan gambar.

\section{HASIL DAN PEMBAHASAN}

\section{Pengelompokan Komunitas Tumbuhan}

Berdasarkan analisis multivariat terhadap hasil analisis vegetasi menggunakan Software Twispan for Windows Version 2.3 menujukan bahwa vegetasi hutan sekunder kampung Mubraidiba dapat dikelompokan menjadi 12 kelompok asosiasi dan 1 kelompok asosiasi soliter. Pengelompokan dilakukan berdasarkan jenis-jenis indikator atau penciri komunitas, sedangkan jenis-jenis indikator ditentukan berdasarkan persentase luas tutupan tajuk (cover presentage) dan jumlah individu suatu jenis tumbuhan dalam petak-petak ukur yang diperhitungkan.

Jenis penciri komunitas atau jenis indikator adalah jenis-jenis yang ditemukan secara berulang-ulang dari total plot atau gampang terlihat dan mendominasi dalam komunitas (Barbour et al. 1981 dalam Achmad 2011), dalam penelitian ini digunakan sebagai dasar perhitungan adalah luasan tutupan tajuk. Jenisjenis tersebut sering dianggap sebagai indikator bagi kehadiran jenis lain dalam kelompok asosiasiasi yang sama. Secara ekologi jenisjenis indikator mempunyai peranan yang sangat besar dalam mempengaruhi kestabilan iklim mikro dan kesuburan tanah di bawah tegakan hutan, sehingga menyediakan habitat yang cocok bagi jenis-jenis lain untuk tumbuh, sebagaimana pada gambar 2 dan 3 .
Gambar 2. Kondisi tegakan secara vertikal di hutan sekunder;

Gambar 3. Pertumbuhan tegakan yang sedang terjadi di hutan sekunder

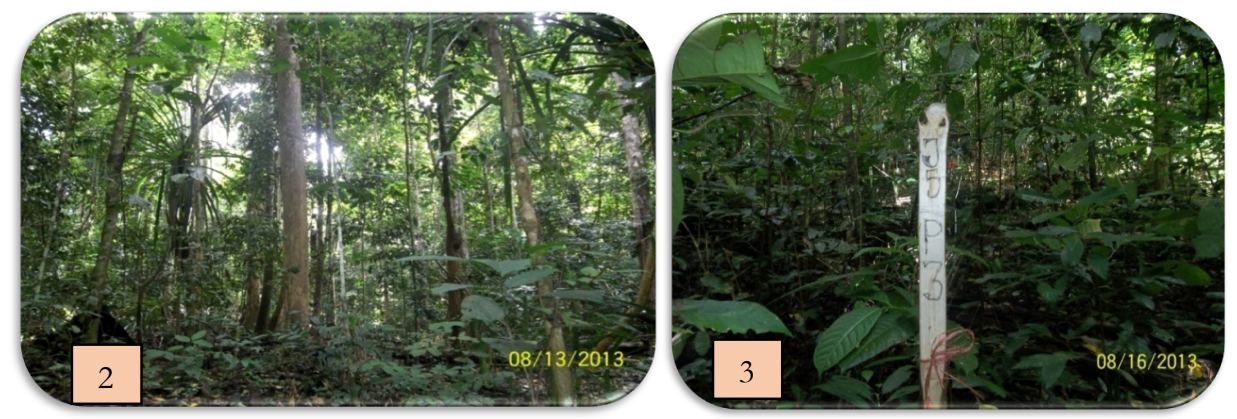

26

(a) Asosiasi Peneliti Biodiversitas Papuasia - Fakultas Kehutanan UNIPA 
Kelompok Asosiasi I

Tabel 2. Jenis-jenis pohon yang membentuk kelompok asosiasi I

\begin{tabular}{|c|c|c|c|c|c|}
\hline \multirow{2}{*}{ Jenis } & \multirow{2}{*}{ Famili } & \multicolumn{4}{|c|}{ Fase pertumbuhan } \\
\hline & & Semai & Pancang & Tiang & Pohon \\
\hline Anisoptera moranti & Dipterocarpaceae & - & - & - & - \\
\hline Aksiodendron sp. & Fabaceae & - & - & - & - \\
\hline Archidendron parviflorum & Fabaceae & - & - & - & - \\
\hline Acthinodaphne nitida & Lauraceae & $\sqrt{ }$ & $\sqrt{ }$ & $\sqrt{ }$ & - \\
\hline Buchanania arborensis & Anacardiaceae & - & - & - & - \\
\hline Campnosperma sp. & Lauraceae & - & - & - & - \\
\hline Celtis latifolia & Cannabaceae & $\sqrt{ }$ & - & - & $\sqrt{ }$ \\
\hline Canaga odorata & Annonaceae & - & - & - & - \\
\hline Cerbera floribunda & Apocynaceae & - & - & - & - \\
\hline Criptocarya sp. & Lauraceae & - & - & - & - \\
\hline Dyospiros discolor & Ebenaceae & - & - & - & - \\
\hline Dracontomelom dao & Anacardiaceae & - & - & - & - \\
\hline Elaiocarpus angustifolius & Elaiocarpaceae & - & - & - & - \\
\hline Endospermum molucanum & Euphorbiaceae & - & - & - & - \\
\hline Gamelina sp. & Lunaceae & - & - & - & - \\
\hline Gonocarium sp. & Cardiopteridaceae & - & - & - & - \\
\hline Hibiscus sp. & Malvaceae & - & - & - & - \\
\hline Hemappasandra sp. & Anacardiaceae & - & $\sqrt{ }$ & - & $\sqrt{ }$ \\
\hline Homalium foetidum & Flaocaurtinaceae & - & - & - & - \\
\hline Litsea tuberculata & Lauraceae & - & - & - & - \\
\hline Lepiniopsis ternatensis & Apocynaceae & - & - & - & - \\
\hline Lunasia amara & Rutaceae & - & - & - & - \\
\hline Litsea timoriana & Lauraceae & - & - & - & - \\
\hline Medushathera laxiflora & Icacinaceae & - & - & - & - \\
\hline Mimosoup sp. & Lauraceae & - & - & - & - \\
\hline Maxtisiodendron pacilados & Rubiaceae & - & - & - & - \\
\hline Neotaclea sp. & Rubiaceae & - & - & - & - \\
\hline Ophionorus susfenscens. & Ophiogalaceae & - & - & - & - \\
\hline Piper anduncum & Piperaceae & - & - & - & - \\
\hline Pipturus sp. & Urticaceae & - & - & - & - \\
\hline Polialtya mubare & Annonaceae & - & - & - & - \\
\hline Rhus taitensis & Meliaceae & - & - & - & - \\
\hline Sterculia macrophylla & Sterculiaceae & - & - & - & - \\
\hline Semecarpus papuana & Anacardiaceae & $\sqrt{ }$ & - & $\sqrt{ }$ & - \\
\hline Teijmaniodendron sp. & Lauraceae & $\sqrt{ }$ & $\sqrt{ }$ & - & - \\
\hline
\end{tabular}

Sumber: Hasil olah data primer, 2014; Keterangan $: \sqrt{ }$ Jenis dominan 
Tabel 2 menujukkan bahwa kelompok asosiasi satu dibentuk oleh 35 jenis pohon yang tergolong dalam 22 famili. Jenis-jenis yang menjadi penciri atau indikator dari kelompok satu menurut tingkat pertumbuhannya adalah untuk tingkat semai terdiri dari A. nitida, $S$. papuana, Teijsmaniodendron sp.,dan $C$. latifolia. Indikator tingkat pancang adalah Hemappasandra sp., $A$. nitida dan Teijsmaniodendron sp. Tingkat tiang adalah jenis $S$. papuana, dan $A$. nitida. Sedangkan tingkat pohon adalah Hemappasandra sp. dan C. latifolia. Kelima jenis indikator tersebut merupakan jenis dengan kemampuan adaptasi yang sangat baik terhadap faktor lingkungan seperti tanah dan iklim sehingga dapat menjadi penciri komunitas pada lebih dari satu tingkat pertumbuhan.

Kemampuan adaptasi dapat disebabkan oleh faktor keturunan (heriditer) atau karena ketersediaan faktor pendukung pertumbuhan (tanah dan iklim) tersedia dalam batas-batas yang diperlukan. Setiadi et al. (1989), menjelaskan bahwa organisme dengan kisaran toleransi terhadap faktor lingkungan luas, akan cenderung tersebar luas. Kecenderungan tersebar luas suatu jenis pohon, sering juga didukung dengan jumlah individu yang sangat banyak pada fase semai dan pancang, bentuk fisik alat perkembangbiakan yang memudahkan proses penyebaran dengan bantuan air, anging atau secara biologi maupun dukungan kondisi topografi (ketinggian dan kelerengan) serta keadaan fisik dan kimia tanah yang cocok untuk tumbuh. Kelompok asosiasi dua terbentuk oleh 22 jenis pohon yang tergolong dalam 18 famili. Jenis indikator untuk semai adalah $S$. javensis, pancang adalah $L$. acueleata.Tingkat tiang adalah $S$. javensis dan L. acueleata. Sedangkan untuk pohon tidak ditemukan jenis indikator. Fase pertumbuhan pohon yang tidak ditemukan jenis indikator menunjukan ciri hutan sekunder bahwa belum ada jenis tingkat pohon yang mampu tumbuh stabil dimana suksesi sedang terjadi sehingga proses adaptasi terhadap kondisi biologi dan fisik tumbuh masih berlangsung dengan demikian ditemukan dua jenis yang dominan di atas. Jumlah jenis pohon dalam kelompok asosiasi tiga adalah 16 jenis dari 11 famili. Jenis indikator untuk tingkat semai adalah $S$. macrophylla, Sisipus sp. dan $K$. pinnatum. Ketiga jenis ini menjadi indikator tingkat semai karena menghasilkan semai yang banyak, sedangkan Sisipus sp. adalah jenis yang tergolong stabil pada tingkat bawah karena merupakan salah satu jenis herba. Sedangkan jenis $K$. pinnatum dan $S$. macrophylla hadir pada tingkat tiang dan pohon, dan merupakan jenis yang dominan pada kelompok asosiasi III.

Kelompk Asosiasi II

Tabel 3. Jenis-jenis pohon yang mmbentuk kelompok asosiasi II

\begin{tabular}{llcccc}
\hline \multirow{2}{*}{ Jenis } & \multicolumn{2}{c}{ Famili } & \multicolumn{5}{c}{ Fase pertumbuhan } \\
\cline { 3 - 6 } & Moreceae & Semai & Pancang & Tiang & Pohon \\
\hline Artocarpus altilis & Meliaceae & - & - & - & - \\
Aglaya spectabilis & Moraceae & - & - & - & - \\
Antiaris tocxicarya & Anacardiaceae & - & - & - & - \\
Buchanania arborensis & Burseraceae & - & - & - & - \\
Canarium hirsutum & Elaiocarpaceae & - & - & - & - \\
Elaiocarpus angustifolius & & - & - & - & - \\
Coffea malayana & Moreceae & - & - & - & - \\
Ficus sp1. & Cardiopteridacear & - & - & - & - \\
Gonocarium sp. & & & & &
\end{tabular}

28

(a) Asosiasi Peneliti Biodiversitas Papuasia-Fakultas Kehutanan UNIPA 


\begin{tabular}{llllll}
\hline Garcinia sp. & Clusiaceae & - & - & - & - \\
Intsia bijuga & Fabaceae & - & - & - & - \\
Koordersiodendron pinnatum & Anacardiaceae & - & - & - & - \\
Litsea timoriana & Lauracae & - & - & - & - \\
Lansium sp. & Meliaceae & - & - & - & - \\
Lea acueleata & Leaceae & - & $\sqrt{ }$ & $\sqrt{ }$ & - \\
Prunus arborea & Rosaceae & - & - & - & - \\
Pimelodendron amboinicum & Euphorbiaceae & - & - & - & - \\
Pometia coreacea & Sapindaceae & - & - & - & - \\
Spathiostemon javensis & Euphorbiaceae & $\sqrt{ }$ & - & $\sqrt{ }$ & - \\
Sterculia urceolata & Sterculiaceae & - & - & - & - \\
Sisipus sp. & Cannabaceae & - & - & - & - \\
Zysygium sp. & Myrtaceae & - & - & - & - \\
\hline
\end{tabular}

Sumber: Hasil olah data primer, 2014; Keterangan $: \sqrt{ }$ Jenis dominan

\section{Kelompok Asosiasi III}

Tabel 4. Jenis-jenis pohon yang membentuk kelompok asosiasi III

\begin{tabular}{|c|c|c|c|c|c|}
\hline \multirow[b]{2}{*}{ Jenis } & \multirow{2}{*}{ Famili } & \multicolumn{4}{|c|}{ Fase pertumbuhan } \\
\hline & & Semai & Pancang & Tiang & Pohon \\
\hline Aksiodendron sp. & Fabaceae & - & - & - & - \\
\hline Canarium hirsutum & Burceraceae & - & - & - & - \\
\hline Dyospiros discolor & Ebenaceae & - & - & - & - \\
\hline Dracontomelom dao & Anacardiaceae & - & - & - & - \\
\hline Gonocarium sp. & Cardiopteridaceae & - & - & - & - \\
\hline Koordersiodendron pinnatum & Anacardiaceae & $\sqrt{ }$ & $\sqrt{ }$ & - & - \\
\hline Medusanthera laxiflora & Rubiaceae & - & - & - & - \\
\hline Neonauclea sp. & Rubiaceae & - & - & - & - \\
\hline Ophionorus susfenscens & Ophiogalaceae & - & - & - & - \\
\hline Pometia coreace & Sapindaceae & - & - & - & - \\
\hline Pimelodendron amboinicum & Euphorbiaceae & - & - & - & - \\
\hline Paraserientes falcataria & Fabaceae & - & - & - & - \\
\hline Sisipus sp. & Cannabaceae & $\sqrt{ }$ & - & - & $\sqrt{ }$ \\
\hline Sterculia macrophylla & Sterculiaceae & $\sqrt{ }$ & - & $\sqrt{ }$ & $\sqrt{ }$ \\
\hline Spatiostemon javensis & Euphorbiaceae & - & - & - & - \\
\hline Timonius timon & Rubiaceae & - & - & - & - \\
\hline
\end{tabular}

Sumber: Hasil olah data primer, 2014; Keterangan $: \sqrt{ }$ Jenis dominan 
Kelompok Asosiasi IV

Tabel 5. Jenis-jenis pohon yang membentuk kelompok asosiasi IV

\begin{tabular}{|c|c|c|c|c|c|}
\hline \multirow{2}{*}{ Jenis } & \multirow{2}{*}{ Famili } & \multicolumn{4}{|c|}{ Fase pertumbuhan } \\
\hline & & Semai & Pancang & Tiang & Pohon \\
\hline Aglaya spectabilis & Meliaceae & - & - & - & - \\
\hline Becaurea sp. & Anacardiaceae & - & - & - & - \\
\hline Criptocarya sp. & Lauraceae & - & - & - & - \\
\hline Ficus nodosa & Moraceae & - & - & - & - \\
\hline Litsea timoriana & Lauraceae & - & $\sqrt{ }$ & $\sqrt{ }$ & - \\
\hline Neotaclea sp. & Rubiaceae & - & - & - & - \\
\hline Rhus taitensis & Meliaceae & - & - & - & - \\
\hline
\end{tabular}

Sumber: Hasil olah data prmer, 2014; Keterangan $: \sqrt{ }$ Jenis dominan

Kelompok empat terdiri dari tujuh jenis dari 5 famili dengan jenis indikator tingkat pancang dan tiang adalah L. timoriana. Jumlah jenis yang sedikit pada suatu kelompok diduga karena dibatasi oleh faktor lingkungan, sehingga hanya jenis-jenis tertentu dengan kemampuan adaptasi tinggi yang dapat tumbuh. Jenis tersebut hadir pada fase pertumbuhan pancang dan tiang sehingga merupakan jenis yang dominan bila dilihat dengan jenis yang lainya.

\section{Kelompok Asosiasi V}

Tabel 6. Jenis-jenis pohon yang membentuk kelompok asosiasi V

\begin{tabular}{llcccc}
\hline \multirow{2}{*}{ Jenis } & \multirow{2}{*}{ Famili } & \multicolumn{5}{c}{ Fase pertumbuhan } \\
\cline { 3 - 6 } & & Semai & Pancang & Tiang & Pohon \\
\hline Aglaia spectabilis & Meliaceae & - & - & - & - \\
Dysoxyllum molisimus & Meliaceae & - & - & - & - \\
Dyospiros discolor & Ebenaceae & - & - & - & - \\
Gnetum gnemon & Gnetaceae & - & - & - & - \\
Hibiscus sp. & Malvaceae & - & - & - & - \\
Macaranga sp & Ephorbiaceae & - & $\sqrt{ }$ & $\sqrt{ }$ & - \\
Malothus sp. & Ephorbiaceae & - & - & - & - \\
Pterygota sp. & Sterculiaceae & - & - & - & - \\
Zysygium sp. & Myrtaceae & - & - & - & - \\
\hline
\end{tabular}

Sumber: Hasil olah data primeer, 2014; Keterangan $: \sqrt{ }$ Jenis dominan

Kelompok lima terdiri dari sembilan jenis dari 7 famili dengan jenis indikator tingkat pancang dan tiang adalah Macaranga sp. Jumlah jenis yang sedikit pada suatu kelompok diduga karena dibatasi oleh faktor lingkungan tetapi juga karena proses suksesi sedang berlangsung, sehingga hanya jenis-jenis tertentu dengan kemampuan adaptasi tinggi yang dapat tumbuh atau menginvasi areal yang masih kosong. Hal ini ditunjukan juga oleh jenis Macaranga sp. sebagai indikator sebab jenis ini adalah jenis pionir. 
Kelompok Asosiasi VI

Tabel 7. Jenis-jenis pohon yang membentuk kelompok asosiasi VI

\begin{tabular}{llllll}
\hline \multirow{2}{*}{ Jenis } & \multicolumn{1}{c}{ Famili } & \multicolumn{5}{c}{ Fase pertumbuhan } \\
\cline { 3 - 6 } Aglaia sp. & Meliaceae & - & - & $\sqrt{ }$ & $\sqrt{ }$ \\
Celtis latifolia & Cannabaceae & - & - & - & - \\
Dyospiros discolor & Ebenaceae & - & - & - & - \\
Ficus benjamina & Moraceae & - & - & - & - \\
Gnetum gnemon & Gnetaceae & - & - & - & - \\
Gymnacranthera fargu & Myristicaceae & - & - & - & - \\
Horsfieldia irya & Myristicaceae & - & - & - & - \\
Harpulea sp. & & - & - & - & - \\
Malothus sp. & Euphorbiaceae & - & - & - & - \\
Maniltoa bronoides & Fabaceae & - & - & - & - \\
Neotacle nofoguensis & Rubiaceae & - & - & - & - \\
Palaquium amboinensis & Sapotaceae & - & - & - & - \\
Polyalti glauca & Annonaceae & - & - & - & - \\
Pometia coreace & Sapindaceae & - & - & - & - \\
\hline
\end{tabular}

Sumber: Hasil olah data primer, 2014; Keterangan $: \sqrt{ }$ Jenis dominan

Pohon-pohon yang membentuk kelompok asosiasi enam berjumlah 14 jenis dari 13 famili. Jenis indikator untuk fase tiang dan pohon adalah Aglaia sp., sedangkan pada fase semai dan pancang tidak ditemukan jenis indikator. Kondisi ini menunjukan bahwa daerah ini baru diinvasi atau suksesi sedang berjalan karena lokasi penelitian adalah hutan sekunder. Jenis-jenis dalam kelompok enam baru saja memasuki masa reproduksi sehingga belum banyak menghasilkan semai atau pancang.

\section{Kelompok Asosiasi VII}

Tabel 8. Jenis-jenis pohon yang membentuk kelompok asosiasi VII

\begin{tabular}{llllll}
\hline \multicolumn{1}{c}{ Jenis } & \multicolumn{1}{c}{ Famili } & \multicolumn{5}{c}{ Fase pertumbuhan } \\
\cline { 3 - 6 } & & Semai & Pancang & Tiang & Pohon \\
\hline Aglaia spectabilis & & - & - & - & - \\
Dracontomelom dao & Anacardiaceae & - & - & - & - \\
Gymnacranthera farguharyana & Myristicaceae & - & - & - & - \\
Hemaphasandra sp. & Anacardiaceae & - & - & - & - \\
Litsea ladermani & Lauraceae & - & - & - & - \\
Maniltoa bronoides & Fabaceae & - & - & - & - \\
Macaranga sp. & Ephorbiaceae & - & - & - & - \\
Pterygota sp. & Annonaceae & - & - & - & - \\
Rhus taitensis & Meliaceae & $\sqrt{ }$ & - & $\sqrt{ }$ & - \\
Polialtya sp. & Annonaceae & - & - & - & - \\
Sisipus sp. & Cannabaceae & - & - & - & - \\
\hline
\end{tabular}


Kelompok asosiasi tujuh terdiri dari 11 jenis yang tergolong dalam 9 famili. Jenis indikator untuk tingkat semai dan pohon adalah Rhus taitensis, sedangkan tingkat pancang dan pohon tidak ada jenis indikator. $R$. taitensis merupakan jenis yang ditemukan dengan kerapatan sangat tinggi pada tingkat semai.

\section{Kelompok Asosiasi VIII}

Tabel 9. Jenis-jenis pohon yang membentuk kelompok asosiasi VIII

\begin{tabular}{llllll}
\hline \multirow{2}{*}{ Jenis } & \multirow{2}{*}{ Famili } & \multicolumn{5}{c}{ Fase pertumbuhan } \\
\cline { 3 - 6 } & & Semai & Pancang & Tiang & Pohon \\
\hline Alstonia scholaris & Apoocynaceae & - & - & $\sqrt{ }$ & $\sqrt{ }$ \\
Anthocephalus cinensis & Rubiaceae & - & - & - & - \\
Chisocheton ceremicus & Meliaceae & - & - & - & - \\
Dysoxilum oktandrum & Meliaceae & - & - & - & - \\
Dracontomelom dao & Anacardiaceae & - & - & - & - \\
Medusanthera laxiflora & Rubiaceae & - & - & - & - \\
Pterygota horsfieldia & Sterculiaceae & - & - & - & - \\
\hline
\end{tabular}

Sumber: Hasil olah data primer, 2014; Keterangan $: \sqrt{ }$ Jenis dominan

Kelompok asosiasi delapan terdiri dari 7 jenis dari 5 famili, dengan indikator jenis pada tingkat tiang dan pohon adalah $A$. scholaris. Sedangkan pada fase semai dan pancang tidak ditemukan adanya jenis yang menjadi indikator.
Jenis A. scholaris adalah jenis yang cepat tumbuh, sering ditemukan sebagai jenis pionir pada areal hutan yang baru mengalami suksesi tetapi juga pada hutan primer terutama pada daerah yang lembab.

\section{Kelompok Asosiasi IX}

Tabel 10. Jenis-jenis pohon yang membentuk kelompok asosiasi IX

\begin{tabular}{llllll}
\hline \multirow{2}{*}{ Jenis } & \multirow{2}{*}{ Famili } & \multicolumn{5}{c}{ Fase pertumbuhan } \\
\cline { 3 - 6 } & & Semai & Pancang & Tiang & Pohon \\
\hline Archidendron parfilorum & Fabaceae & - & - & - & - \\
Becaure sp. & Anacardiaceae & - & - & - & - \\
Dysoxilum mollucanum & Meliaceae & - & - & - & - \\
Ficus sp1. & Moraceae & - & - & - & - \\
Horsfieldia irya & Myristicaceae & - & - & - & - \\
Pterygota sp. & Sterculiaceae & - & - & - & - \\
Pisonia umbelifera & Icacinaceae & - & - & - & - \\
Arcidendron parviflorum & Fabaceae & - & - & - & - \\
\hline
\end{tabular}

Sumber: Hasil olah data primer, 2014; Keterangan : - jenis tidak lengkap

Kelompok asosiasi sembilan terdiri dari 8 jenis yang tergolong dalam 7 famili. Pada kelompok ini tidak ditemukan adanya jenis indikator atau penciri dari setiap fase pertumbuhan.
Kondisi semacam ini menunjukan bahwa penyebaran setiap jenis hampir merata sehingga tidak ditemukan adanya suatu jenis yang lebih menonjol yang dapat berperan sebagai jenis indikator. 
Kelompok Asosiasi X

Tabel 11. Jenis-jenis pohon yang membentuk kelompok asosiasi $X$

\begin{tabular}{llllll}
\hline \multicolumn{1}{c}{ Jenis } & \multicolumn{1}{c}{ Famili } & \multicolumn{4}{c}{ Fase pertumbuhan } \\
\cline { 3 - 6 } & & Semai & Pancang & Tiang & Pohon \\
\hline Archidendron parviflorum. & Fabaceae & $\sqrt{ }$ & $\sqrt{ }$ & - & - \\
Aglaia sp. & Meliaceae & - & - & - & - \\
Homalium foetidum & Flaocaurtinaceae & - & - & - & - \\
Koordersiodendron pinnatum & Anacardiaceae & - & - & - & - \\
Litsea ladermani & Lauraceae & - & - & - & - \\
Ophionorus sp. & Ophiogalaceae & - & - & - & - \\
Pipturus sp. & Urticaceae & - & - & - & - \\
\hline
\end{tabular}

Sumber: Hasil olah data primer, 2014; Keterangan $: \sqrt{ }$ Jenis dominan

Kelompok 10 adalah asosiasi dari 7 jenis pohon yang tergolong dalam 7 famili, dengan jenis indikator untuk fase semai dan pancang adalah $A$. parviflorum.
Jenis tersebut merupakan jenis indikator karena sangat mampu beradaptasi sehingga mampu menyebar lebih merata dari jenis lain.

Kelompok Asosiasi XI

Tabel 12. Jenis-jenis pohon yang membentuk kelompok asosiasi XI

\begin{tabular}{llcccc}
\hline \multicolumn{1}{c}{ Jenis } & \multicolumn{1}{c}{ Famili } & \multicolumn{4}{c}{ Fase pertumbuhan } \\
\cline { 3 - 5 } Calophyllum inophylum & Clusiaceae & - & $\sqrt{ }$ & $\sqrt{ }$ & - \\
Canarium hirsutum & Burceraceae & - & - & - & - \\
Canaga odorata & Annonaceae & - & - & - & - \\
Ficus sp1. & Moraceae & $\sqrt{ }$ & - & - & $\sqrt{ }$ \\
Linociera sp. & Oleaceae & - & - & - & - \\
Ophionorus sp. & Ophiogalaceae & - & - & - & - \\
Octomeles sumatrana & Datiscaceae & - & - & - & - \\
Ocrasia barbonica & Apocynaceae & - & - & - & - \\
Paraserientes falcataria & Mimosaceae & - & - & - & - \\
Timonius timon & Rubiaceae & - & - & - & - \\
\hline
\end{tabular}

Sumber: Hasil olah data prmer, 2014; Keterangan $: \sqrt{ }$ Kelompok asosiasi pada jenis - jenis dominan

Kelompok asosiasi 11 terbentuk dari 10 jenis pohon yang terdiri dari 10 famili, dengan indikator jenis tingkat semai dan pohon adalah Ficus sp1., untuk tingkat pancang dan tiang adalah C. inophylum. Jenis-jenis yang menjadi indikator pada fase semai dan pancang menunjukan bahwa jenis tersebut mempunyai kerapatan yang relatif tinggi sedangkan indikator fase tiang menunjukan luas tutupan tajuknya tinggi. 
Kelompok Asosiasi XII

Tabel 13. Jenis-jenis yang membentuk kelompok asosiasi XII

\begin{tabular}{llllll}
\hline \multicolumn{1}{c}{ Jenis } & \multicolumn{1}{c}{ Famili } & \multicolumn{4}{c}{ Fase pertumbuhan } \\
\cline { 3 - 6 } & Meliaceae & - & - & - & - \\
\hline Aglaia sp. & Apocynaceae & - & - & - & - \\
Cerbera floribunda & Lauraceae & - & - & - & - \\
Campnosperma sp. & Rutaceae & - & - & - & - \\
Euodia elleryana & Myristicaceae & - & - & - & - \\
Gymnacranthera farguharyana & Myristicaceae & - & - & - & - \\
Myristica fatua & Sapotaceae & - & - & - & - \\
Palaquium amboinensis & Euphorbiaceae & - & - & - & - \\
Pimelodendron amboinicum & Anacardiaceae & - & - & - & - \\
Semecarpus papuana & Kemang & &
\end{tabular}

Sumber: Hasil olah data primer, 2014; Keterangan : - Kelompok jenis tidak lengkap

Kelompok Asosiasi Soliter

Tabel 14. Jenis-jenis yang membentuk kelompok asosiasi soliter

\begin{tabular}{|c|c|c|c|c|c|}
\hline \multirow{2}{*}{ Jenis } & \multirow{2}{*}{ Famili } & \multicolumn{4}{|c|}{ Fase pertumbuhan } \\
\hline & & Semai & Pancang & Tiang & Pohon \\
\hline Chisocheton ceremicus & Meliaceae & $\sqrt{ }$ & - & $\sqrt{ }$ & - \\
\hline Criptocarya sp. & Lauraceae & - & $\sqrt{ }$ & $\sqrt{ }$ & - \\
\hline Canarium hirsutum & Burceraceae & $\sqrt{ }$ & $\sqrt{ }$ & - & - \\
\hline Dysoxyllum molisimus & Meliaceae & - & - & - & - \\
\hline Euodia elleryana & Rutaceae & $\sqrt{ }$ & - & - & $\sqrt{ }$ \\
\hline Elaiocarpus angustifolius & Elaiocarpaceae & - & - & - & - \\
\hline Ficus sp1. & Moreceae & - & - & - & - \\
\hline Hibiscus sp. & Malvaceae & - & - & - & - \\
\hline Litsea ladermani & Lauraceae & - & $\sqrt{ }$ & $\sqrt{ }$ & - \\
\hline Lunasia amara & Rubiaceae & $\sqrt{ }$ & $\sqrt{ }$ & - & - \\
\hline Litsea ladermani & Lauraceae & - & - & - & - \\
\hline Maniltoa bronoides & Fabaceae & - & - & - & - \\
\hline Octomeles sumatrana & Dasticaceae & - & - & - & - \\
\hline Palaquium amboinensis & Sapotaceae & - & - & - & - \\
\hline Polyalti glauca & Annonaceae & - & - & - & - \\
\hline Pimelodendron amboinicum & Sapotaceae & - & - & - & - \\
\hline Pometia coreacea & Sapindaceae & - & - & - & - \\
\hline Sterculia macrophylla & Sterculiaceae & - & - & - & - \\
\hline Zysygium sp. & Myrtaceae & - & - & - & - \\
\hline
\end{tabular}

Sumber: Hasil olah data primer, 2014; Keterangan $: \sqrt{ }$ Jenis dominan 
Kelompok asosiasi 12 terbentuk oleh 9 jenis pohon dari 8 famili, tanpa adanya jenis indikator. Kondisi semacam ini merupakan petunjuk bahwa kesembilan jenis pada tabel 4 . adalah jenis-jenis yang penyebaran dan tutupan tajuknya rata-rata hampir sama di hutan sekunder.

Kelompok asosiasi soliter adalah jenis-jenis tumbuhan yang mampu hadir di hutan sekunder Mubraidiba tanpa adanya asosiasi dengan jenis
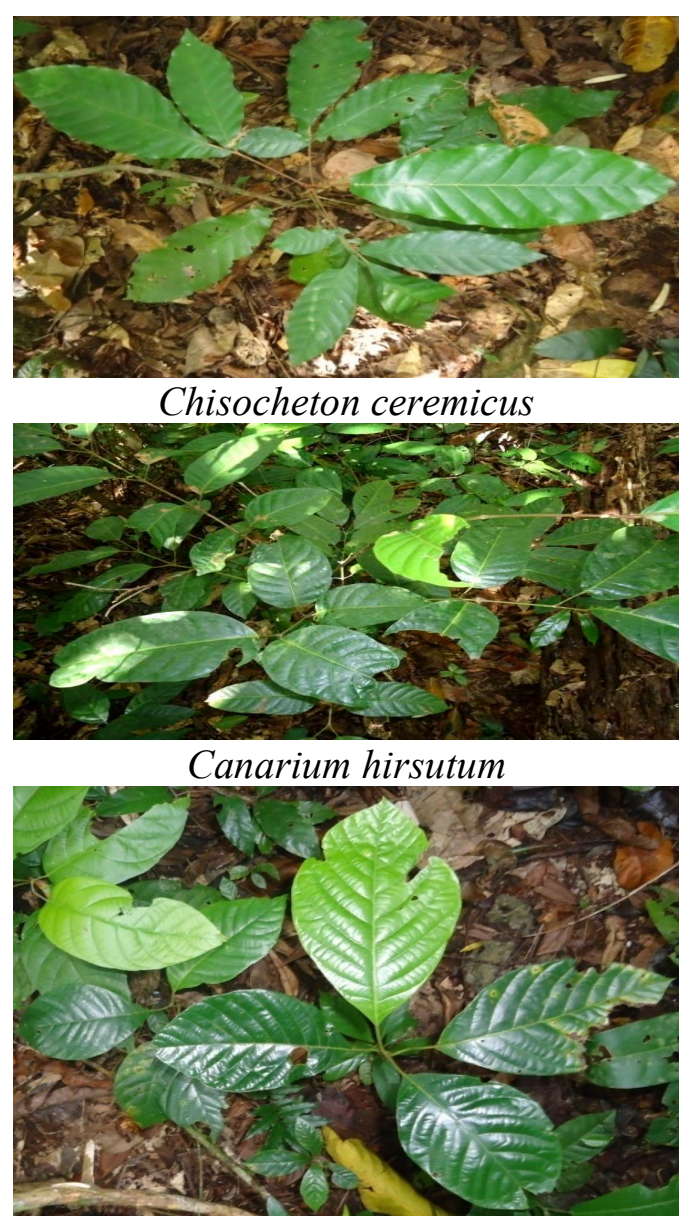

Litsea ladermanii lain. Jumlah jenis dalam kelompok ini adalah 19 yang terdiri dari 16 famili. Jenis indikator fase semai $C$. ceremicus, $C$. hirsutum, E. elleryana dan L. amara. Jenis indikator fase pancang Criptocarya sp. L. ladermani, $L$. amara dan $C$. hirsutum. Jenis indikator untuk fase tiang $C$. ceremicus, L. ladermani dan Criptocarya sp. Jenis indikator untuk tingkat pohon adalah E. elleryana. Berikut adalah 6 jenis yang paling dominan seperti pada Gambar 4.

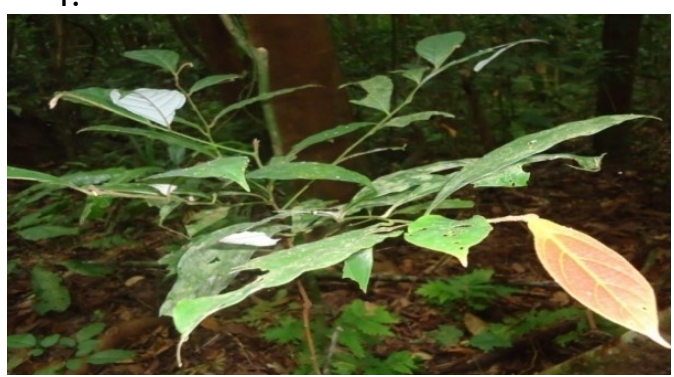

Cryptocaria $\mathrm{sp}$.

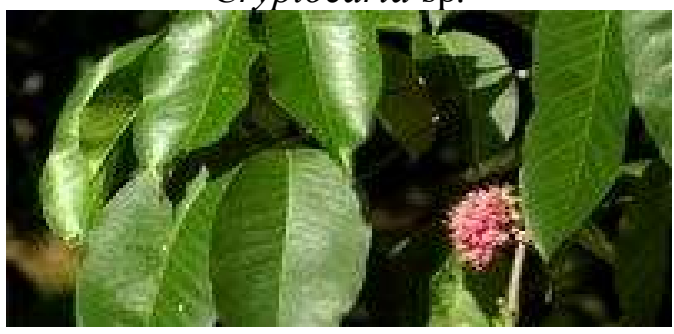

Euodia elleryana

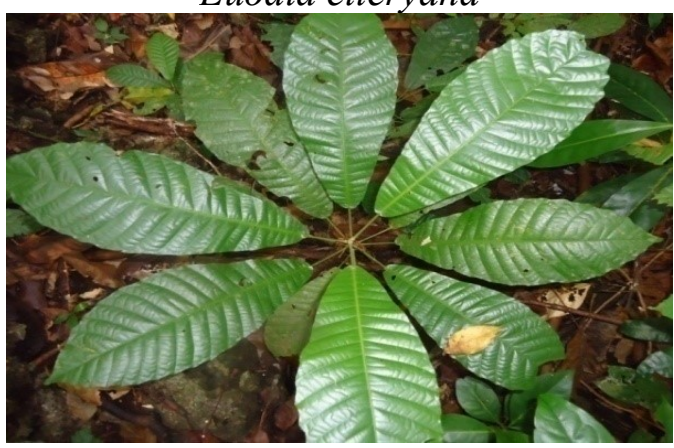

Lunasia amara

Gambar 4. Jenis dominan pada kelompok asosiasi soliter.

Jenis -jenis diatas merupakan jenis yang berasal dari hutan primer dan sangat dominan berdasarkan kelompok solitary pada hutan sekunder dikampung Mubraidiba. Namun masih terdapat jenis lainnya yang tercantum pada kelompok asosiasi I-XII yang hanya jenis tertentu merupakan jeni-jenis dominan. Jenis tersebut adalah jenis indicator yang menyusun 
hutan sekunder di kampung Mubraidiba Distrik Manokwari Utara.

\section{KESIMPULAN}

Jumlah jenis penyusun hutan sekunder di kampung Mubraidiba adalah 24 jenis yang tergolong dalam 15 famili. Jenis tersebut merupakan jenis yang dominan dan merupakan indikator hutan sekunder. Jumlah kelompok asosiasi dari hutan sekunder adalah 12 kelompok asosiasi dan 1 kelompok asosiasi soliter dimana kelompok tersebut adalah hasil analisis software Twinspan yang menunjukan bahwa jenis tersebut adalah jenis yang dominan. Kondisi tingkat keanekaragaman spesies pada kawasan kelas hutan tergolong melimpah atau tinggi dengan tingkat kestabilan ekosistem dalam proses suksesi dan proses regenerasi alami dalam kondisi normal.

\section{DAFTAR PUSTAKA}

Achmad A. 2011. Rahasia ekosistem hutan bukit kapur. Surabaya: Brilian Internasional.

Lamprecht H. 1986. Waldbau in den tropen. Parey, Hamburg.

Beers TW. 1962. Components of forest growth. Journal of Forestry. 60(4): 245-248.
Catterson TM. 1994. Strategies for the valorization of secondary forests as a resource for development: A Position Paper for GTZ (Second Draft).

Minnesota Department of Natural Resources. 2007. A handbook for collecting vegetation plot data in minnesota; the releve method. Minnesota Country Biological Survey, Minnesota Natural Heritage And Nongame Research Program, and Ecological Land Classification Program. Biological report 92. St. paul: Minnesota Department of Natural Resources.

Mueller-Dombois D, H. Ellenberg. 1974. Aims and methods of vegetation ecology. New York: John Wiley \& Sons.

Prasetyo D. 2006. Komposisi dan struktur tegakan serta pertumbuhan jeniskomersial di hutan rawa gambut IUPHHK PT. Diamond Raya Timber. Propisi Riau.

Setiadi D, Tjondronegoro PD, Yusron A. 1989. Bahan ajar dasar-dasar ekologi. Departeman Pendidikan dan Kebudayaan, Direktorat Pendidikan Tinggi, Pusat Antar Universitas Ilmu Hayat IPB.

Soerianegara I dan A. Indrawan. 2005. Ekosistem hutan indonesia. Laboratorium Ekologi Hutan, Fakultas Kehutanan IPB. Bogor. 